\title{
GOLPE EN LA CÁTEDRA
}

\section{María Olivia Mönckeberg ${ }^{1}$}

El Salón de Honor de la Universidad de Chile, en la Alameda, fue escenario el lunes 10 de septiembre de 1973 de un encuentro poco académico con el que culminó el movimiento civil que provocó el quiebre de la democracia en Chile. Solo faltaban horas para que la Marina, el Ejército, la Fuerza Aérea y Carabineros tomaran las armas.

Esa mañana el recinto estaba repleto cuando llegaron el líder de los camioneros, León Vilarín; el empresario y presidente de la Sociedad de Fomento Fabril, Sofofa, Orlando Sáenz; y Julio Bazán, quien encabezaba la Federación de Colegios Profesionales y técnicos.

Entre los asistentes apareció también el joven abogado Jaime Guzmán Errázuriz, forjador del Movimiento Gremial Universitario, nacido en la Universidad Católica y que en 1983 dio origen a la Unión Demócrata Independiente, UDI. El motivo formal de la convocatoria era la constitución del Comando Multigremial de Santiago.

Desde ese acto, transmitido en directo por los micrófonos de Radio Agricultura, los dirigentes contrarios al Gobierno de la Unidad Popular clamaban a voz en cuello para que Salvador Allende Gossens renunciara a la Presidencia de la República.

En los momentos en que los altos mandos de las Fuerzas Armadas daban las secretas puntadas finales para lo que denominaron el "pronunciamiento", los más conocidos "comandantes civiles" del Golpe llegaron hasta la principal Universidad del país a manifestar en público sus inclaudicables puntos de vista.

Se discutía por esos días la posibilidad de un plebiscito para dirimir el profundo conflicto existente en Chile. Pero los dirigentes gremiales no estaban interesados en fórmulas políticas. El rotundo contenido del encuentro tiñó todos los discursos.

León Vilarín, el canoso presidente de los transportistas, era uno de los más activos adversarios del gobierno de la Unidad Popular. Dos largos paros de camioneros que sumaron adeptos de diversos gremios, su estilo aguerrido y sus beligerantes declaraciones lo mantenían en el primer plano desde 1971. Bajo de estatura, de enérgico mentón, León Vilarín fustigaba con su elocuente palabra esa mañana del 10 de septiembre. Aludiendo al presidente Salvador Allende, el dirigente camionero señaló que no le pediría el mismo sacrificio de José Manuel Balmaceda: "Solo le pido el sacrificio de O'Higgins".

A lo largo de su vibrante discurso salpicado de sardónicas expresiones referidas al mandatario socialista, León Vilarín reiteró su pedido. "Los camioneros de Chile ya no

1. El texto de este artículo es una versión revisada del primer capítulo del libro La privatización de las universidades en Chile. Una historia de dinero, poder e influencias, Santiago de Chile: Editorial Copa Rota, 2005.

María Olivia Mönckeberg Pardo es profesora titular de la Universidad de Chile y directora del Instituto de Comunicación e Imagen. Premio Nacional de Periodismo 2009. 
luchamos por el chasis, por el neumático, por el repuesto o la tarifa. Eso quedó atrás en el reiterado incumplimiento de las promesas del gobierno, si es que todavía hay un saldo de gobierno en Chile", ironizó.

Vítores y aplausos interrumpían cada cierto rato y daban más ínfulas al enardecido orador. Y un grito coreado por los asistentes atronaba en el Salón de Honor: "iiQue se vaya!!, ¡iQue se vaya!!”.

Hacia el final de su intervención, León Vilarín insistió en su demanda dirigida al presidente Allende. "Hay una sola solución para todos los problemas de Chile: que usted haga dejación del cargo... Ya nadie quiere soluciones parciales... Aquí no hay negociación, no hay transacción. Se equivocan los políticos que piensan que se le pueda dar al gobierno la ventaja de la rectificación... Se pasó la hora de la rectificación".

Más aplausos inundaron el Salón de Honor... Más gritos de la concurrencia.

"Y en cuanto a la idea del plebiscito — proseguía Vilarín—, yo me permitiría rogarles a todos los periodistas democráticos que no gasten palabras ni tinta ni papel en esa idea. El plebiscito, si lo hay, lo tiene que presidir un gobierno que infunda respeto a todos los chilenos. ¡Ese gobierno, hay que decirlo de una vez, tienen que presidirlo las Fuerzas Armadas de Chile!".

La ovación duró algunos minutos. Los aplausos esta vez fueron acompañados de otra consigna: "¡Crear, crear, poder militar!”, con la misma entonación que el entonces conocido eslogan izquierdista "Crear, crear, poder popular".

Dos estudiantes fueron aplaudidos masivamente cuando el locutor los mencionó por el esfuerzo desplegado en la organización del acto: José Yuraszeck Troncoso ${ }^{2}$ y Pedro Corona Bozzo ${ }^{3}$. Ambos tendrían amplia figuración años más tarde en la historia que se empezó a tejer al día siguiente.

2. El ingeniero José Yuraszeck Troncoso fue subdirector de Odeplan en 1982, gerente de la Compañía Chilena de Electricidad desde 1983, encabezó el proceso de privatización de esa empresa y logró años después el control de Endesa. Tras su estrepitosa caída en 1997, obtuvo suculentas ganancias por la venta de Endesa; compró la principal productora de sal. En julio del 2005 la Corte Suprema obligó a pagar una millonaria multa de 160 millones de dólares al grupo de siete ejecutivos encabezados por Yuraszeck. La sanción la había impuesto la Superintendencia de Valores y Seguros en 1997 por las oscuras operaciones realizadas al vender las acciones que tenían en las Chispas a Endesa España. Yuraszeck es miembro de la Comisión Política de la UDI, pero después que la Corte Suprema le ratificó la multa, el ex zar de la electricidad decidió suspender temporalmente su participación en esa instancia. Más antecedentes en el libro de María Olivia Mönckeberg, El saqueo de los grupos económicos al Estado chileno, Ediciones B, 2001, y "José Yuraszeck, En la hora de pagar", en revista El Periodista, No 86, año 3, 22 de julio de 2005. Actualmente Yuraszeck es el presidente del Club Deportivo Azul-Azul que administra el club deportivo que lleva el nombre de Universidad de Chile.

3. Pedro Próspero Corona Bozzo, contador auditor, fue presidente de la Cámara Nacional de Comercio hasta 2008 y actualmente es su tesorero. En la dictadura fue ejecutivo de confianza del Gobierno militar en CODELCO. Gerente de recursos humanos de la principal empresa estatal en los primeros años después del Golpe, en 1978 el general Augusto Pinochet lo designó vicepresidente de Comercialización y Administración. En 1979 pasó a ser vicepresidente de Finanzas, donde permaneció hasta 1985. Participó desde ese puesto en el directorio del Instituto de Seguros del Estado, ISE. En 1988, cuando el grupo Penta tomó el control de la AFP Cuprum, Corona fue designado presidente de la AFP. 


\section{LA VOZ DE GUZMÁN}

Jaime Guzmán Errázuriz entró a estudiar Derecho en 1963 a la Universidad Católica y después continuó como profesor de esa Facultad. Dotado de una gran capacidad oratoria desde niño, el forjador del Movimiento Gremial Universitario era un ferviente admirador del ex presidente de la República Jorge Alessandri Rodríguez ${ }^{4}$, a quien solía visitar.

Desde el triunfo de Allende, Jaime Guzmán se caracterizó como uno de sus principales opositores. A través de las pantallas de la naciente televisión chilena, su imagen y su voz llegaron a ser conocidos mucho más allá de los escenarios, donde habitualmente se movía. Su palabra era escuchada con especial atención dentro de círculos civiles y militares.

En una "breve, concisa y brillante intervención", citada por el profesor Danilo Salcedo Vodnizza en su libro La Universidad de Chile y su Reforma inconclusa ${ }^{5}$, Guzmán indicó aquella mañana del 10 de septiembre que "la única conspiración que el señor Allende debía tomar en cuenta era aquella que se desprendía de la etimología de la palabra", pues "conspiración", según el fundador del gremialismo venía de "común aspiración". Y "la común aspiración del pueblo de Chile que ha sido repetida por todos es ique se vaya!", sentenció.

Jaime Guzmán fue tajante en ese improvisado discurso:

—La hora de la rectificación pasó. Aquí el señor Allende sabe que él no está en condiciones de solucionar los problemas del pueblo de Chile, que lo primero y más fundamental que un gobernante necesita para dar solución a los problemas de su pueblo es la confianza de sus gobernados. Y la confianza, lo mismo que el honor perdido, no se recupera jamás.

\section{CON DISTINTA MIRADA}

Aunque había sido originalmente simpatizante de izquierda, Danilo Salcedo, sociólogo y profesor de Historia, fue una de las figuras destacadas del "Frente Universitario" que se opuso a la Unidad Popular en la Universidad de Chile. En septiembre de 1973, integraba el Consejo Normativo Superior y fue uno de los oradores de ese acto del día 10, donde habló a nombre de los académicos de la "U". En 2005, cuando lo entrevisté para el libro La privatización de las universidades. Una historia de dinero, poder e influencias, me

4. Jorge Alessandri Rodríguez, presidente de Chile entre 1958 y 1964, hijo del dos veces presidente Arturo Alessandri Palma. Ingeniero civil de profesión, dedicado a actividades empresariales, independiente de derecha, fue senador antes de ser elegido presidente con el apoyo del Partido Conservador y del Partido Liberal, con los que gobernó. Murió el 31 de agosto de 1986.

5. Salcedo, D., La Universidad de Chile y su reforma inconclusa, Santiago de Chile: Editorial Nascimento, 1975.

6. Según el Diccionario de la Real Academia de la Lengua, RAE, "Conspirar es la acción de conspirar; unirse contra un superior o un particular". Y la cuarta acepción del verbo "conspirar" alude a "concurrir varias cosas a un mismo fin". 
explicó que pertenecía al grupo de "los académicos independientes". Los denominaban los "academicistas", porque no estaban en ningún partido político 7 . "Constituimos lo que se llamó la Acción Reformista Universitaria, ARU, que fue una de las fuerzas académicas más importantes de la Universidad de Chile y que contribuyó a elaborar lo que considerábamos una ideología universitaria para Chile".

En una conversación que sostuvimos en 1987 a propósito de la crisis generada por la designación del rector delegado José Luis Federici en la Universidad de Chile, Salcedo me confesó su arrepentimiento por la actitud de entonces y por el rol jugado por la agrupación en esos años:

-Algunos de nosotros, con mayor ingenuidad que otros, participábamos en esa lucha así llamada libertaria que parecía tan patriota destinada a terminar con la Unidad Popular. Y hacíamos causa común con todos esos sectores gremiales. Me siento totalmente culpable de aquello, porque ahí hubo personas que después hicieron cosas tan contrarias a lo que ahí se manifestó.

En su libro publicado en 1975, Danilo Salcedo recordaba con entusiasmo el acto del 10 de septiembre, organizado por el Frente Universitario que reunía a profesores de la derecha tradicional y a gremialistas. En su preparación — relata — se trabajó intensamente en la oficina del profesor Fernando Valenzuela Erazo, quien en el régimen militar fue decano de la Facultad de Filosofía y Educación. Colaboraron activamente en aquella oportunidad algunos estudiantes. Entre ellos, Salcedo recuerda a José Yuraszeck, Gustavo Letelier, Andrés Etchegaray, Eugenio Figueroa e Ignacio Astete.

En cambio -indica Salcedo-, "pronto se nos informó que la Democracia Cristiana Universitaria no aprobaba este acto de apoyo a los gremios y que estaba instruyendo a sus militantes para que no concurrieran al evento organizado por los gremialistas e independientes de derecha".

\section{AQUELLA NOCHE DE LUNES}

Destacado médico y profesor universitario, Alfredo Jadresic Vargas nació en Iquique el 18 de septiembre de 1925, el mismo día en que fue promulgada la Constitución Política, en el gobierno de Arturo Alessandri Palma.

Ex alumno del Colegio San Agustín, del Liceo Barros Arana y de la Universidad de Chile, se tituló en 1950. Mientras estudiaba en la Facultad de Medicina, Alfredo Jadresic fue dirigente estudiantil y atleta. Llegó a ser campeón sudamericano de salto alto en 1949, y ese año representó a Chile en la Olimpíada de Londres, y a la Federación de Estudiantes, FECH, en el segundo Congreso Mundial de Estudiantes de Medicina que se celebró unas semanas más tarde en la capital inglesa.

Veinte años después, Jadresic, especialista en endocrinología, fue elegido decano de Medicina y encabezó la reforma que marcó una época en la historia de la facultad más

7. Entre ellos estaban los profesores Luis Izquierdo, Juan Morales Malva, Fernando Valenzuela Erazo y Fernando Vargas, quien después apoyó a la Unidad Popular. 
prestigiada del país. Hombre de izquierda, fue el rival del rector Edgardo Boeninger en la elección de 1969, apoyado por las fuerzas de la Unidad Popular en la Universidad.

En esa oportunidad resultó elegido secretario general de la Universidad el compañero de lista de Jadresic: el profesor Ricardo Lagos Escobar ${ }^{8}$. Abogado y economista, había sido profesor en Derecho y en Economía, dirigió la Escuela de Ciencias Políticas y Administrativas y el Instituto de Economía. Lagos llegó a ser el primer presidente de Chile del siglo XXI, algo más de treinta años después.

Para el ex decano Jadresic, ese lunes 10 de septiembre había sido un día como cualquier otro. Seguía siendo profesor de la Universidad de Chile en el departamento de Salud Pública y era asesor del Ministerio de Salud. Alfredo Jadresic estuvo un corto tiempo en el Partido Comunista, del que después se alejó. "Fue una cosa muy fugaz, porque cuando empecé a conocer cómo funcionaba el Partido, hice críticas y se produjo el inicio de un debate interno que no logró seguir porque vino el Golpe. Fui atraído por los socialistas y los comunistas porque tenían la mejor gente que conocía en la Universidad. Pero cuando comencé a participar en forma orgánica y vi que dentro del Partido no se daba el debate que hubiera querido, dejé de participar".

Vivía con su mujer Patricia Samsing y sus seis hijos, en la calle Alvaro Casanova, en el sector alto de La Reina. "Como a las doce y media de la noche del lunes me llamó por teléfono un vecino, a quien había conocido en tiempos de deportista. Él era en ese momento entrenador de esquí del Ejército". Relata la conversación:

-Alfredo, vengo de una reunión social con militares y uno de los generales dijo de repente que se tenían que retirar, porque mañana es el Golpe militar. Al escucharlo, no supe qué hacer. Por eso te estoy llamando.

Tras la conversación con su vecino, Jadresic tomó de nuevo el teléfono y se comunicó con José Cademartori, el ministro de Economía, militante PC, casado con Xenia Dujesin, descendiente de yugoeslavos y amiga por generaciones de la familia Jadresic... "Nunca más me acordé de esa conversación hasta que hace unos meses, comiendo aquí en mi casa, Pepe Cademartori me contó que después de hablar conmigo había llamado a una persona cercana a Allende y le había avisado. Pero también he sabido después que el Presidente tuvo informaciones semejantes por distintos conductos".

\section{"UN ALZAMIENTO EN VALPARAÍSO"}

Otro destacado médico, el doctor Enrique Paris, psiquiatra, profesor de la Facultad de Medicina y miembro del Comité Directivo y del Consejo Superior de la Universidad de

8. Ricardo Lagos Escobar, presidente de Chile 2000-2006, nació en 1938. Estudió en el Instituto Nacional y en la Universidad de Chile. En 1960, a los 22 años, terminó Derecho. Su memoria de título La concentración del poder económico fue aprobada con distinción máxima y se convirtió rápidamente en un éxito editorial con cinco ediciones publicadas. Después se doctoró en Economía en la Universidad de Duke en Estados Unidos. Fue profesor en la Universidad de Chile desde 1963 hasta 1971, director de la Escuela de Ciencias Políticas y Administrativas de 1967 a 1969, y entre 1971 y 1972 dirigió el Instituto de Economía. 
Chile, tenía entonces cuarenta años y era la principal figura del Partido Comunista y de la Unidad Popular en esa Universidad.

Asesor de Salvador Allende y miembro del Comité Central del PC, Enrique Paris tuvo noticias del inminente Golpe pasada la medianoche del lunes 10. "Parece que hay un alzamiento en Valparaíso", fue el comentario que hizo a un grupo de amigos, después de hablar por teléfono con otro dirigente de la máxima instancia comunista. Sus palabras confirmaban los rumores que había mencionado otro de los asistentes a la última tertulia nocturna en la que él participó.

Todos, salvo Enrique Paris, éramos periodistas del equipo de la revista Debate Universitario de la Universidad Católica ${ }^{9}$, del Consejo Superior de la Universidad. La mayoría, democratacristianos o simpatizantes.

Nos encontramos esa noche en mi casa de la calle Luis Carrera con Las Hualtatas, en Vitacura, para despedir a quien había sido nuestro director hasta unas semanas antes, el periodista Oscar González Clarke. Asumió la dirección en su reemplazo Juan Pablo Cárdenas ${ }^{10}$ —actual director de Radio Universidad de Chile- y decidimos juntarnos a compartir una copa de vino y algo para comer.

Enrique era en ese tiempo la pareja de la periodista Marcia Scantlebury, quien trabajaba también en Debate, y fue con ella — como otras veces— a nuestra comida. Hubo esa noche una ausencia notoria: Patricia Lutz, integrante de nuestro equipo, hija del general director de Inteligencia Militar, quien a última hora se excusó de asistir. Su padre le advirtió que se recogiera temprano esa noche, porque el Golpe sería "al día siguiente".

Patricia llamó por teléfono a mi casa y habló con Oscar González, a quien le pidió que me avisara "para que los echara temprano". Esas versiones ya no eran nuevas, pero la fuente en esta oportunidad parecía digna de crédito. Con todo, la conversación continuó en medio de bromas nerviosas y extraños augurios, y nadie se fue antes de la una.

Hace un tiempo Patricia Lutz me contó por qué su padre le había "soltado la información". Preparábamos un reportaje para Debate sobre el amor. Ella tenía asignado el "amor a la patria" y había concertado una entrevista sobre el tema con su "tío Augusto", el comandante en jefe del Ejército. El general Lutz se demudó cuando su hija le contó que el martes 11 pretendía ir al Ministerio de Defensa. Ella adivinó que algo muy especial sucedía y finalmente él terminó por confesarle.

9. La revista Debate Universitario fue creada bajo la rectoría de Fernando Castillo Velasco, en 1971, como órgano de comunicación del Consejo Superior de la Universidad Católica.

10. Juan Pablo Cárdenas Squella egresó de la Universidad Católica en 1970. En 1977 fue fundador de la revista Análisis y director durante toda la existencia de ese medio hasta principios de 1992. La revista dejó de existir en abril de 1973. Actualmente, Juan Pablo Cárdenas es director de la Radio Universidad de Chile y profesor de la Escuela del Instituto de Comunicación e Imagen de la misma Universidad. Obtuvo el Premio Nacional de Periodismo en 2005. 


\section{EL DÍA SIGUIENTE}

Esa madrugada, Enrique Paris se trasladó a La Moneda, junto al Presidente Salvador Allende. Ahí lo encontró el bombardeo. Fue uno de los prisioneros del palacio presidencial. Lo llevaron ese mismo día al regimiento Tacna que estaba al mando del entonces comandante Joaquín Ramírez Pineda. Lo que sucedió después no se termina de aclarar.

Danilo Salcedo, cuando sostuvimos esa entrevista en 2005, mantenía vivos los recuerdos de esos días:

-Ese martes 11 en la mañana estaba en mi casa. Como a las nueve y media, hablé con Marcia Scantlebury, y me enteré que Enrique estaba en La Moneda. Inmediatamente llamé a don Egidio, el papá de Enrique, porque pensé que Enrique lo podía llamar. Le ofrecí mi casa. "A mi casa no van a entrar los militares, porque no tengo nada que ver con la Unidad Popular" - le dije. Creo que anotó el domicilio y le di mi teléfono.

Durante cuatro días, cuenta Salcedo, recorrió postas y hospitales: "Me reuní con la gente del Frente Universitario, porque se había dado la información que Enrique tenía la úlcera perforada y había ido a parar al Hospital del Salvador. Germán Bañados Alonsa, primo político mío y amigo de Enrique, trabajaba en ese hospital y recorrió todos los servicios, pero Enrique no estaba. Otro abogado fue al Estadio Nacional... ¡Yo me fui a la Posta Central a ver los cadáveres! Y no había ningún rastro".

A pesar de que estaban en posiciones muy distintas, el ex dirigente del Frente Universitario asegura: "Con Enrique Paris éramos grandes amigos. A veces — dice- nos tomábamos solos los dos una taza de té en el despacho de Raúl Bitrán, el secretario general de la Universidad". El relato de Salcedo no parece exagerado. Corresponde a ese Chile anterior al Golpe, donde pese a la encarnizada lucha política e ideológica, aún subsistía en muchas partes y entre muchas personas la posibilidad de conversar, aunque pensaran diametralmente distinto.

"Cuando en el Consejo Universitario la gente de la UP que llevaban para gritarme trataba de no dejarme hablar, Enrique se paraba y exigía silencio para escuchar al académico Salcedo", recuerda Danilo Salcedo, mientras su rostro delgado se comprimía en un gesto de impotencia. La voz se le quiebra mientras golpea con el puño sobre su mesa de trabajo: “Enrique París!...”.

\section{LA UNIVERSIDAD RODEADA}

La Universidad de Chile fue desde el mismo martes 11 de septiembre de 1973 un blanco de la represión que se instaló en el país. Muchos de quienes formaban parte de la comunidad universitaria hasta el día antes, perdieron la vida, desaparecieron o tuvieron que exiliarse. Otros pasaron a la clandestinidad o se vieron obligados a dejar sus puestos.

El martes 11 "entraron los uniformados y violaron algunas puertas de la Casa Central, sobre todo las que daban a la calle San Diego, al parecer con el propósito de encontrar armas en la Universidad de Chile. Lo más que pudieron encontrar fueron los cortapapeles en las oficinas", recordaba Salcedo. 
En la sede Oriente trabajaba en 1973 la historiadora María Eugenia Horvitz, ex mujer de Enrique Paris, actualmente vicedecana de la Facultad de Filosofía y Humanidades de la Universidad de Chile. Ella al momento del Golpe dirigía el Departamento de Historia de la Facultad de Filosofía.

María Eugenia Horvitz era comunista en esa época. "A las seis de la mañana me avisaron que efectivamente el Golpe se iniciaba. Lo que teníamos que hacer era partir a los lugares donde trabajábamos. Por eso, me fui al antiguo Pedagógico de Macul, antes de llegar a la Avenida Grecia, donde estaba la sede Oriente de la Universidad de Chile y hoy es la Universidad Metropolitana de Ciencias de la Educación, la UMCE".

Los tres niños, hijos de su matrimonio con Paris, vivían con ella. El mayor, Enrique, de once años, alcanzó a irse al colegio Manuel de Salas y después se tuvo que volver a la casa del arquitecto Miguel Lawner, recuerda María Eugenia. Los dos menores, Sebastián en ese entonces de diez años, y la Quenita de siete, se quedaron en la casa, en Marchant Pereira.

Junto a María Eugenia Horvitz estaban esa mañana en la sede del Pedagógico otros connotados profesores del PC: el historiador Hernán Ramírez Necochea ${ }^{11}$, el integrante del Consejo Normativo Superior y dirigente comunista Fernando Ortiz Letelier ${ }^{12}$, padre de Estela Ortiz, la viuda de José Manuel Parada, sociólogo comunista degollado en 1985, y la geógrafa Graciela Uribe, secretaria general de la sede.

A las diez y media sonó el teléfono. Atendió Fernando Ortiz. Era la voz de Enrique Paris desde La Moneda. Le comentó a su amigo que la situación estaba muy grave.

—No alcancé a llegar al teléfono — recuerda María Eugenia Horvitz—, porque se me ocurrió la cosa más loca: como tenía las llaves del Departamento de Historia, me fui a la biblioteca a buscar en los libros de arquitectura colonial el plano de La Moneda, para ver si tenía, unos subterráneos profundos, como alguna vez me lo habían enseñado. Y cuando venía con el libro donde lo comprobaba para mostrárselo a Fernando Ortiz, él me dijo:

-Oye, vuelve a la realidad, Enrique acaba de llamar y no sé si vamos a poder volver a hablar con él.

María Eugenia Horvitz les insistía:

—No les va a pasar nada, porque La Moneda es un verdadero bunker, ellos pueden meterse a los subterráneos. Mira, cuánto miden... - Y me quedé tranquila, sin imaginar lo que ocurriría un rato después.

11. Hernán Ramírez Necochea, historiador, profesor titular de la Facultad de Filosofía y Educación desde 1952 hasta 1973, fue asimismo decano de la Facultad, y a través de su obra fue un gran impulsor de la historia social en Chile. Es autor, entre otros libros, de La contrarrevolución de 1991, La historia del imperialismo en Chile y La historia del movimiento obrero en Chile. Militante comunista, se asiló en Francia, donde murió en 1979, sin volver a su país.

12. Fernando Ortiz Letelier, profesor de Historia, era miembro del Consejo Normativo Superior de la Universidad de Chile y dirigente del Partido Comunista. Detenido-desaparecido, fue secuestrado el 15 de diciembre de 1976. Padre de Estela Ortiz, la viuda de José Miguel Parada Maluenda, uno de los dirigentes comunistas degollados en marzo de 1985. 
Estudiantes y profesores habían llegado hasta la sede Oriente, que fue rodeada por militares del Regimiento de Telecomunicaciones. En ese campus estaban las facultades de Filosofía, de Ciencias Sociales, de Educación y de Ciencias, la que hoy está todavía en Las Palmeras, en el actual Campus Juan Gómez Millas.

La sede Oriente era "la más grande de la Universidad", recuerda María Eugenia Horvitz, quien para ilustrar su afirmación indica que la Universidad de Chile en el año 2005 tenía 23 mil estudiantes en total, y en ese momento solo la Sede Oriente contaba con 15 mil.

Soledad Bianchi Laso también se dirigió al Pedagógico esa mañana. Tenía 25 años, era ayudante del Departamento de Castellano y estaba siguiendo un doctorado. Aunque sus padres eran de derecha, ella era una militante de base del Partido Comunista. Y como la "orden de partido" era concurrir a los "lugares de trabajo", en caso de un golpe, Soledad partió a la Universidad desde su casa en Bernarda Morín con la Avenida Salvador antes de las ocho. Visto ahora le parece una locura. "Mi mamá lloraba cuando yo salí de la casa, se sabía que ya había movimiento militar", pero "era joven, no dimensionaba y nunca pensamos que todo eso iba a ser como fue".

Casada con el pintor y Premio Nacional de Artes Plásticas 2007 Guillermo Núñez, con quien vivió el exilio en Francia, Soledad Bianchi, ex profesora de Literatura de la Facultad de Filosofía y Humanidades se sorprende de su "increíble ingenuidad" de aquel entonces. Recuerda una ilustrativa escena de esa mañana: "Los milicos, no sé si del Ejército o de la FACH, estaban rodeando el Pedagógico, y yo me acerqué a uno y le pregunté: ¿Usted es leal?".

En pocos minutos se dio cuenta que las cosas habían tomado otro cariz. Que ya no había lealtades con el Presidente Allende. "Empezó el susto de que los cabros le gritaran a los milicos y nos dispararan. Era el caos... Muchas cosas se me han borrado... hasta que empezamos a ver los aviones que bombardearon La Moneda...", me decía Soledad Bianchi en 2005.

Al poco rato — continuaba - "nos llamaron a una reunión de todos los comunistas del Pedagógico. La sala estaba llena. Fue en el Departamento de Historia y habló Fernando Ortiz. Estaba también la Kena Horvitz. Él era profesor y dirigente y nos dijo que nos fuéramos tranquilos a nuestras casas".

- Cuando vimos que empezaban a poner ametralladoras en los edificios colindantes, nos reunimos y decidimos evacuar el Pedagógico para evitar una masacre — señala María Eugenia Horvitz.

"Como los jardines son muy abiertos, constituían un alto riesgo. Así es que hicimos un trato y salimos por la puerta de lo que era la Escuela de Periodismo que daba a Juan Gómez Millas, la pequeña calle que lleva el nombre del ex rector; esta sale a Doctor Johow, la que lleva hacia la Plaza Nuñoa", relata la historiadora.

El sociólogo Eduardo Ruiz, vicerrector de la sede, y Fernando Ortiz llevaron las conversaciones con los militares — recuerda María Eugenia Horvitz- y los cientos de estudiantes y profesores pudieron abandonar el campus cercado. 


\section{UNA REUNIÓN QUE NO FUE}

Edgardo Boeninger, senador institucional hasta marzo de 2006 y ministro secretario general de la Presidencia de Patricio Aylwin entre 1990 y 1994, era el rector de la Universidad de $\mathrm{Chile}^{13}$ en el momento del Golpe. Boeninger, en ese entonces un ingeniero sin militancia política, había sido director de Presupuesto del gobierno del Presidente Eduardo Frei Montalva, desde 1964 y, simultáneamente era decano de Economía en la Universidad de Chile. Hasta que en 1969 fue elegido rector por la comunidad universitaria, de acuerdo a los procedimientos establecidos por la Reforma de fines de los años 60 .

En 1973, Boeninger — quien murió en el año 2009— presidía también el Consejo de Rectores de las universidades chilenas que congregaba a las máximas autoridades de las ocho instituciones existentes en el país.

A las nueve de la mañana de ese martes 11 el rector Boeninger tenía prevista una importante reunión. Este es su relato:

"Estaba embarcado en ese momento en el esfuerzo de última hora por devolverle la decisión al pueblo de Chile, en el sentido de generar la renuncia colectiva de los parlamentarios y la del Presidente Allende, de manera que se eligiera todo de nuevo".

Me contó el ex rector: "Teníamos ya el acuerdo de los parlamentarios democratacristianos para que presentaran su renuncia en una notaría, condicionada a que también se produjera la renuncia del Presidente, para que todo se eligiera de nuevo. Incluso el mismo Allende podría postular. La idea era devolverle al pueblo la decisión. Se me ocurrió tratar de aplicar al país la solución que había resultado exitosa en la Universidad de Chile".

—La reunión iba a ser en la oficina de Claudio Orrego Vicuña ${ }^{14}$, en la Avenida Bustamante, en el Centro de Estudios Políticos, pero Claudio no llegó. Pusimos la radio y escuchamos la despedida de Salvador Allende por Radio Magallanes, con Jaime Lava$\operatorname{dos}^{15}$. Después del discurso me di cuenta que no había más que hacer, y me fui —me contó Boeninger.

"Tomé el auto de la rectoría de la Universidad de Chile que usaba y salí a la Plaza Italia", continúa el relato del ex rector. "Estaba lleno de tanques, de milicos con sus armas en la mano, y seguí por Providencia hacia arriba, en medio de los tanques. Al pasar por las calles interiores, recuerdo la imagen de jóvenes que se despedían de chiquillas.

13. Edgardo Boeninger, ingeniero civil y economista. Fue director de Presupuesto del Gobierno de Eduardo Frei Montalva entre 1964 y 1969. En 1965 fue decano de la Facultad de Ciencias Económicas de la Universidad de Chile. Fue elegido rector en 1969 y estuvo hasta 1973. Semanas después entró a militar al PDC. Bajo la dictadura, fue elegido vicepresidente en la mesa encabezada por Patricio Aylwin en la Junta Nacional de 1987. Desde 1990 a 1994 Boeninger fue ministro Secretario General de la Presidencia de Patricio Aylwin y uno de los artífices del período de transición en la vuelta a la democracia. Desde 1997 y hasta marzo de 2006 fue senador institucional en calidad de ex ministro de Estado.

14. Claudio Orrego Vicuña en ese entonces era diputado democratacristiano. Falleció en 1982. Es padre del ex alcalde de Peñalolén y precandidato del PDC para las primarias de Concertación en junio del 2013, Claudio Orrego Larraín.

15. Jaime Lavados Montes, licenciado en filosofía y médico neurólogo, fue rector de la Universidad de Chile entre 1990 y 1998. 
Seguramente eran militantes de izquierda que preveían que se les caía el mundo encima. Me fui a mi casa y desde ahí, a través del teléfono, traté de seguir los acontecimientos".

\section{CAÑONES CONTRA LA UTE}

La casa central de la Universidad Técnica del Estado ${ }^{16}$ iba a ser la sede de un muy particular acontecimiento. La tarde antes había quedado dispuesto el estrado y las sillas en el frontis del edificio para la solemne inauguración que sería a las once de la mañana de ese martes 11, de las "Jornadas Antifascistas". El invitado principal era nada menos que el presidente de la República, Salvador Allende, quien tenía previsto, en su discurso, anunciar la convocatoria a un plebiscito.

El secretario general de la Universidad, Ricardo Núñez Muñoz ${ }^{17}$ —quien entre 1990 y 2010 fue senador y en varias oportunidades presidente del Partido Socialista - se había ocupado de afinar los detalles para la transmisión del discurso con los encargados de la OIR, la Oficina de Informaciones y Radiodifusión de la Presidencia de la República. La radio de la UTE sería la cabeza de una cadena nacional que difundiría las palabras del mandatario.

"El Presidente iba a convocar a este plebiscito que desgraciadamente no había sido todo lo bien acogido al interior de su gobierno, lo que mirado con la perspectiva del tiempo habría sido una gran solución para Chile", me comentaba el ex senador Ricardo Núñez, quien prácticamente no durmió esa noche del lunes 10.

Núñez se había acostado alrededor de las seis de la mañana del martes después de una larga reunión donde finalmente llegaron a acuerdo para poner en marcha el 17 de septiembre el canal de televisión de la Universidad Técnica. "El director iba a ser Sergio Ortega, el autor de la canción "Venceremos", el gran compositor comunista que murió en 2003 en París". Estaban construyendo una antena en la calle Cumming, y habían arrendado una casa para el estudio. "Pensábamos que iba a tener una actuación destacada con motivo del Te Deum del 18", recuerda.

A las ocho de la mañana, Ricardo Núñez recibió un llamado de su jefe de Gabinete. Le avisó que muy temprano, alrededor de las seis, que un comando militar había asaltado las instalaciones de la radio que estaban dentro del recinto de la Universidad. Los equipos fueron totalmente destruidos.

16. La Universidad de Chile y la Universidad Técnica del Estado eran las dos únicas universidades estatales al momento del Golpe militar y hasta 1981, cuando el Gobierno decidió cortar las sedes regionales a estas universidades. En el caso de la Universidad de Chile, le fue separado el Instituto Pedagógico y fue constituida la Universidad Metropolitana de Ciencias de la Educación, UMCE. Otras carreras fueron Bibliotecología, Diseño y Servicio Social, con las que constituyó el Instituto Profesional de Santiago, que después dio origen a la Universidad Tecnológica Metropolitana, UTEM. La Universidad Técnica fue transformada en la Universidad de Santiago, USACH.

17. Ricardo Núñez Muñoz es profesor de Historia y Geografía y licenciado en Sociología. Fue senador por la región de Atacama entre 1990 y 2010. Fue vicepresidente del Senado entre 1994 y 1996. Ha sido presidente del Partido Socialista en tres períodos. 
Víctor Jara, el popular cantautor, trabajaba entonces en el departamento de Extensión Musical de la Universidad Técnica. Logró atravesar parte de Santiago hasta llegar al campus de la Alameda con Ecuador, tras un largo rodeo para evitar el encuentro con las patrullas militares que ocupaban la ciudad. Su esposa, Joan, calcula que a la misma hora que Víctor entraba a la sede de la UTE, los aviones de la Fuerza Aérea bombardeaban el Palacio de Gobierno. "Desde los edificios universitarios era posible ver los reactores Hawker Hunter y oír los proyectiles que estallaban al caer sobre La Moneda", relata en su libro Victor Jara: Un canto inconcluso.

En el amplio recinto próximo a la Villa Portales se reunieron cerca de mil estudiantes y profesores. Los disparos atravesaban el centro de Santiago. Transitar por las calles implicaba un riesgo vital. Se anunció que el toque de queda entraría en vigencia esa tarde.

Ricardo Núñez relata que la mayor parte de los estudiantes dirigidos por la Federación y un grupo importante de profesores se concentró en la Escuela de Artes y Oficios. "Deben haber sido entre ochocientas o mil personas. En la Casa Central quedó muy poca gente. Muchos permanecieron en las facultades".

-El cerco empezó muy temprano — continúa Núñez. Mientras se producía el asalto a La Moneda ya había un contingente de un regimiento que vino de La Serena, según supimos después. La Universidad posteriormente fue rodeada. Era muy difícil salir. Por cierto, revisaban a todo el mundo. Finalmente, yo logré hacerlo a las cuatro de la tarde para dirigirme a un cordón industrial.

Tres horas antes, el presidente de la Federación de Estudiantes, el comunista Osiel Núñez, había llamado "a la resistencia en una enfervorizada asamblea", señalan los periodistas Ascanio Cavallo y Margarita Serrano en una reconstitución de escena publicada en 2003. "Pero —indican — no tenían los medios para intentarlo, ni armas, ni defensas, ni planes"18. Como último saludo al Presidente muerto, los estudiantes levantaron una bandera a media asta en la puerta del edificio de la rectoría.

\section{NOCHE DE BALAS}

Según Joan Jara, el rector de la Universidad Técnica Enrique Kirberg "negoció con los militares la autorización para que los encerrados en el edificio permanecieran allí toda la noche, por su propia seguridad, hasta que a la mañana siguiente se levantara el toque de queda. Eso fue lo acordado y se dieron órdenes para que todos permanecieran en el interior de los edificios de la Universidad. Probablemente fue entonces cuando Víctor me telefoneó por segunda vez. No me dijo que el campus estaba rodeado de tanques y soldados".

Se estima que unas seiscientas personas quedaron dentro del recinto. El resto había salido durante el día. En la noche los disparos no cesaron.

18. "Las 24 horas que estremecieron a Chile", Especiales de La Tercera, publicado con motivo de los treinta años del Golpe militar, septiembre de 2003. Taller de Producción Periodística Universidad Adolfo Ibáñez, dirigido por los profesores Ascanio Cavallo y Margarita Serrano. 
El tableteo de las ametralladoras y los disparos de fusiles repiqueteaban cada cierto rato. "Pedro Cariaga, carabinero de 23 años que hacía guardia en el recinto ubicado frente a la Escuela de Artes y Oficios, cayó de un balazo mortal en la cabeza", consignan Cavallo y Serrano. Dentro de la Universidad, el fotógrafo Hugo Araya, militante socialista, recibió una bala en la espina dorsal que le causó la muerte.

"En la noche del 11 al 12, los disparos de francotiradores militares mataron al fotógrafo de la Universidad, cuando los jóvenes se movilizaban por los pasillos. Desde la Universidad no hubo disparos. Siempre se dijo que se había muerto un carabinero...", señala Ricardo Núñez, y cuenta que él —que se había retirado temprano del recinto-, cuando estuvo preso posteriormente, fue acusado de la muerte de ese policía. "Nunca hubo constancia de que se hubiera muerto a alguien ni del Ejército ni de la Comisaría de Carabineros que estaba muy cerca", agrega.

Ricardo Núñez no recuerda haber visto armas dentro de la Universidad. Admite que podrían haber existido "algunas pistolas, pero por los testimonios que he recogido nunca hubo un enfrentamiento armado. Todos los relatos que he conocido dicen que en la noche hubo balazos provenientes de francotiradores que se ubicaron en edificios que rodean la Universidad y que le disparaban a cuanto objeto se movía y ahí mataron al fotógrafo".

Antes de las siete de la mañana del miércoles 12 aparecieron por la Avenida Ecuador artilleros del Ejército. Instalaron un cañón en la calle que enfrenta a la Casa Central. A las siete cinco minutos fue disparado el primer obús. Destrozó parte de la secretaría general donde estaban todos los archivos del Consejo Superior. Un segundo cañonazo atravesó un sector de servicios.

Después del bombardeo, el rector Kirberg y el presidente de la Federación de Estudiantes salieron agitando una camisa blanca. Los militares "sacaron a la gente de los recintos de la Universidad, la pusieron boca abajo a través de la Avenida Ecuador. Muchos pasaron al Estadio Chile y la mayor parte terminó en el Estadio Nacional a donde llegué el 28 de septiembre", cuenta Ricardo Núñez.

Otro de esos prisioneros era Víctor Jara. Lo mantenían aislado en el sector de las graderías del estadio que hoy lleva su nombre. Había sido maltratado y torturado. Su cuerpo sin vida apareció en la calle junto a otros cadáveres el 16 de septiembre.

El estudiante Gregorio Mimica fue liberado tras su paso por el Estadio Chile. "Era un muchacho muy conocido de la juventud comunista. Después de soltarlo lo siguieron y lo volvieron a tomar. Lo llevaron a la Universidad y, por lo que se ha sabido, fue asesinado ahí: lo metieron dentro de una caldera. Nunca se supo la razón de por qué lo liberaron del Estadio y lo llevaron después para asesinarlo a la Universidad", señala Ricardo Núñez.

\section{EN MEDIO DE RUMORES}

La Moneda fue bombardeada. Allende había muerto. La Junta de Gobierno encabezada por el general Augusto Pinochet e integrada por el almirante José Toribio Merino, el 
general de la FACH Gustavo Leigh y el Director de Carabineros César Mendoza, tomó en unas horas el control absoluto del país. Las universidades fueron cercadas y ocupadas. Los medios de comunicación de izquierda, clausurados. Los otros, sometidos a estricto control. Y quienes formaban parte del movimiento que dio origen al Golpe, daban cuenta de las hazañas y proyectos de los vencedores, denostaban a los caídos y silenciaban el resto. Las informaciones y rumores corrían de boca en boca, en voz baja, mientras la población sobrevivía bajo Estado de Sitio y riguroso toque de queda.

Las incansables búsquedas por comisarías, postas, regimientos, por estadios transformados en campos de concentración; los telefonazos a quienes pudieran saber algo, marcaron esos días para familiares y amigos de los cientos de personas de las que nada se sabía.

En ese ambiente el rector de la Universidad de Chile Edgardo Boeninger supo que Enrique Paris había desaparecido. Tuvo un gran impacto al recibir la noticia y trató por diferentes medios de obtener información sobre su paradero. "Era mi adversario principal. El jefe del Partido Comunista en la Universidad de Chile. Pero, además, un tipo al que yo quería mucho. Teníamos muy buenas relaciones personales. Lo apreciaba sinceramente. Un hombre muy simpático, inteligente, nada de burócrata ni acartonado", me comentó.

Unas semanas después, el abogado y profesor de la Facultad de Derecho, Eugenio Velasco Letelier, quien se movió intensamente para ubicar a Enrique Paris, le informó a Boeninger que había muerto. El abogado Velasco le dio también la amarga noticia a doña Norma Roa, la madre del médico, el 9 de octubre de 1973. Justamente ese día Enrique Paris Horvitz, el hijo mayor del asesinado dirigente, cumplía doce años.

Pero ni los más cercanos familiares y amigos tienen certeza todavía si perdió la vida en el regimiento Tacna, por los maltratos recibidos, o si fue fusilado en el campo militar de Peldehue. Enrique Paris sigue en calidad de desaparecido.

\section{POR QUÉ OCULTARSE}

"Inmediatamente después del Golpe — recuerda Alfredo Jadresic_ llamé a Enrique Silva Cimma ${ }^{19}$ que era miembro del Consejo Universitario durante la Reforma y nos hicimos muy amigos".

-Mira, Enrique, he llamado a unas 18 personas y nadie contesta el teléfono. No me he podido ubicar con ningún amigo. ¿Qué piensas tú, que estarán muy temerosos? Ven para conversar, me dijo. Llegué unos minutos después a verlo. ¿Qué crees que debo hacer? ¿Me tendré que ocultar?

— ¿Por qué te vas a ocultar? — cuenta Jadresic que le respondió Silva Cimma. No has hecho nada. Entregaste el decanato en noviembre del año pasado. Eso pasa por la

19. El abogado Enrique Silva Cimma fue profesor emérito de la Universidad de Chile, contralor general de la República, ministro de Relaciones Exteriores de Patricio Aylwin y senador institucional —como ex contralor- entre 1998 y 2006. Murió en 2012. 
auditoría de la Universidad, por la Contraloría General de la República, todas esas cosas están en orden. Tú no tienes ningún cargo de responsabilidad política. ¡Si te toman a ti se levanta la Universidad!...

—Enrique, si han bombardeado La Moneda. Ha muerto el Presidente de la República. ¿Cómo puedes imaginar que se levante la Universidad si me pasa algo a mí? —replicó Jadresic.

Más de treinta años después, el ex decano Jadresic reflexionaba: "Lo que más me impresiona al recordar esas palabras es que reflejan ese inmenso sentido de legalidad de los chilenos. Era lo que sentía un hombre de derecho como Enrique Silva Cimma".

Pocos previeron la magnitud de la tragedia. Edgardo Boeninger reconocía en esa conversación que sostuve con él en 2005:

-Yo nunca estuve con el Golpe, pero sí estuve convencido de que era inevitable. Le hice un informe a Patricio Aylwin, quien presidía el PDC, tres meses antes del Golpe, junto a Claudio Orrego, a Jaime Lavados y Alvaro García padre. Nos juntamos un fin de semana para hacer un análisis político de la situación. Debe haber sido en junio de 1973. Yo todavía no era militante del Partido Demócrata Cristiano en ese tiempo. Nuestra conclusión fue que el Golpe era inevitable. Recuerdo que incluso hablamos de "golpe evolutivo" y "golpe gorila". Entendíamos por "evolutivo" uno que terminara rápidamente. Nos parecía más probable un golpe "gorila", en el sentido de militares de línea dura, pero no teníamos la impresión de que esto pudiera durar 17 años.

Alfredo Jadresic tampoco previó lo que podría ocurrir con él y con otros. El lunes 17 de septiembre volvió a la Universidad de Chile al Departamento de Salud Pública.

-De repente, llegó Jorge Ávila, un muchacho que era becario recién recibido de Psiquiatría y preguntó qué hacía porque lo habían llamado para presentarse a través de los bandos. Mi ingenuidad fue tal que le dije: "Por supuesto, preséntate, ¿qué te va a pasar?, si tú no has hecho nada"... No sé si era del MIR, y les bastaba ese hecho...".

Y concluye Jadresic con pesar: "Lo tomaron preso el 17 de septiembre y al día siguiente lo fusilaron en el Estadio Nacional. Me quedé con una carga emocional que la he visto repetida en varios relatos de otras personas, pensando cómo no haberlo podido alertar".

\section{PRISIONERO DE GUERRA}

Ese 18 de septiembre era el cumpleaños de Alfredo Jadresic, pero el ánimo no estaba para festejos. "Además, no había nada en ninguna parte y nosotros vivíamos en las laderas del cerro en lo que se llamaba Reservas Turísticas, en La Reina Alto". Eran sitios de cinco mil metros y el suyo, con forma de triángulo, lindaba abajo con el de Nicanor Parra. Uno de sus vecinos se preocupó de preparar un pisco sour para celebrar el 18 de septiembre y recordar el cumpleaños del médico. Venía subiendo la bandeja con el trago a la hora de almuerzo, por un camino por el que subían los niños, cuando llegó un auto negro con un chofer y unos hombres armados que dijeron ser agentes de Investigaciones. Uno de ellos dijo que quería hablar con el doctor Jadresic. 
- Me preguntó si tenía información sobre un señor Blanco... Le dije que no. Me pidió entonces, todavía con tono amable, si lo podía acompañar a la oficina para una declaración. Les expliqué que era mi cumpleaños y les dije si podía ir después de almuerzo. No, si son unos minutos no más. Y de un viaje me subieron al auto y me llevaron al Cuartel Central de Investigaciones al centro de Santiago. Pasaron unas tres horas. Todo era caótico, incluso las órdenes que daban los militares. Eran ya las seis de la tarde. Y les pregunté: “¿Qué significa esto, es que yo estoy detenido?".

—No doctor —me dijo el tipo-. Usted no está detenido. Usted es prisionero de guerra.

Lo condujeron al Ministerio de Defensa y después al Estadio Nacional. Un rato después de llegar, un militar lo llevó al camarín número dos, donde encerraron a los "casos especiales" 20 . Allí estuvo dos meses antes de partir al exilio a Inglaterra. "Era un calabozo subterráneo, con ventanas altas por las que no se alcanzaba a ver el cielo. Después de dos o tres semanas en las que no nos dejaban salir a las graderías del Estadio, fue un impacto para mí ver el color azul del cielo y el verde del pasto de la cancha de fútbol", recuerda Alfredo Jadresic.

El médico y ex campeón sudamericano de atletismo, que en sus años de juventud había sido un asiduo del Estadio Nacional y conocía cada uno de sus rincones, continúa:

- No me llamaban nunca para interrogarme hasta que un día un tipo lo hizo y otro me dio un culatazo. Entonces me hicieron esperar contra un murallón, frente al velódromo. De repente alguien gritó.

— ¡Alfredo Jadresic! ¡Siéntese!

— ¿Qué hace usted? — preguntó otro militar de tropa.

- Soy profesor de la Facultad de Medicina.

- Muy complicada esta huevá. ¡Pa' fuera!

Después de esperar unos veinte minutos, apareció un militar vestido de campaña, que por la presencia y manera de hablar cuidada era obviamente un oficial, según recuerda el médico.

— ¿Doctor Jadresic? ¿Usted era decano de la Facultad de Medicina? ¿Y usted ha estado en Inglaterra?

—Sí, claro —le dije—, y él siguió hablándome en inglés, lo que en esa época era bien poco usual.

— ¿Usted fue candidato a rector, no es cierto? ¿Compitió con Boeninger?

-Sí, claro.

— ¿Trabajaba en el Área Norte? ¿Y conoce al doctor René Orozco?

-Sí, por supuesto, es el vicerrector de la sede.

20. Entre los doce "casos especiales" que compartían el camarín-celda con el doctor Alfredo Jadresic estaban Jorge Godoy, ministro del Trabajo; Augusto Jiménez, Laureano León y Waldo Suárez, subsecretarios; Darío Pavez, presidente de la Corporación de Fomento, CORFO; Ociel Núñez, presidente de la Federación de Estudiantes de la Universidad Técnica del Estado; Sandor Arancibia, Carlos Naudon, Mario Céspedes, Nelson Ávila, Adrián Vásquez. Después incorporaron a Vicente Sotta. 
—Ah, ¿lo conoce? Voy a llamarlo por teléfono — dijo el militar y tomó un aparato.

De acuerdo al relato del doctor Jadresic, aparentemente, atendió Orozco por el otro lado de la línea.

-Doctor Orozco, lo estoy llamando del Estadio Nacional, estoy interrogando al doctor Alfredo Jadresic — dijo el militar.

El diálogo con el prisionero se interrumpió. El uniformado respondía con monosílabos, señala el ex decano. A pesar del tiempo transcurrido, los sonidos aún están en su memoria:

-Ah... mmm... Sí... Sí.

Pasado un rato, el militar terminó la conversación telefónica con una frase en clave:

—Entonces x2a; no... x2b.

El uniformado cortó la comunicación y se dirigió nuevamente al médico prisionero. Cambió el tono, se acabó la amabilidad, el coloquio en inglés y le advirtió en tono seco:

- Mire, doctor Jadresic, tenemos toda la información sobre usted. Váyase con mucho cuidado, porque puede correr grandes riesgos aquí.

Con esas palabras — recuerda Alfredo Jadresic_- el oficial dio por terminado el interrogatorio.

\section{TENSIÓN EN EL FRENTE}

El rector Boeninger encaraba a mediados de septiembre otro tipo de problemas en la Universidad de Chile:

—Un sector importante de los profesores, los "academicistas", encabezados por Danilo Salcedo plantearon que no aceptaban que la gente de izquierda que pertenecía al Comité Directivo siguiera participando en las sesiones. Incluso yo forcé una reunión del Comité con los integrantes de izquierda que podían asistir a la sesión y manifesté que mi criterio era que debían continuar. Eso provocó mucha tensión con Salcedo y otros integrantes de ese grupo.

Danilo Salcedo admitió que en el Frente Universitario las opiniones estaban muy divididas y que su posición era diferente a la del rector:

-Edgardo Boeninger era contrario a la intervención militar. En cambio muchos de nosotros, entre los que me incluyo, creíamos que era indispensable para evitar la guerra civil en el país, porque como profesor de historia tenía absoluta confianza de la honorabilidad, profesionalismo, honestidad, dignidad y cumplimiento de la palabra empeñada de las Fuerzas Armadas. Como todo "pelota" chileno, creía en las instituciones nacionales. Incluso, en alguna reunión en la sede Norte manifesté que creía indispensable poner orden en la casa, porque de lo contrario este país se iba a desgarrar en una guerra civil. Por eso, yo prefería la intervención de las Fuerzas Armadas. Algunos se sorprendieron porque se suponía que yo no era un hombre militarista ni tampoco he estado nunca vinculado a la derecha chilena. 
— ¿Pero se identificó con la derecha en esos días del Frente Universitario? —le pregunté en una conversación sostenida en su departamento en la comuna de Las Condes, en enero de 2005.

-No, no he sido nunca de derecha. Me han dicho muchas cosas. He sido investigado en Estados Unidos como agente de la Unión Soviética. Como espía. Y parece que era porque estaba preparando un viaje a la Unión Soviética.

- ¿Y de espía de Estados Unidos no lo han acusado?

- Nunca he sido espía de Estados Unidos. Algunos creen que soy de la CIA. Un periodista inventó eso a los pocos días del Golpe, que me había escapado de Chile con los dólares de la Universidad de Chile. Y apareció eso en un diario en México. Y el que viajaba a Estados Unidos era mi hijo Danilo Andrés Salcedo Norman, con su madre, y yo estaba en Chile.

Salcedo explica sus planteamientos de aquel entonces:

-Estábamos hablando a los pocos días después del Golpe y la conclusión a que uno llegaba después de un análisis me llevaba a preguntar: ¿qué ganaba la Universidad de Chile con tener gente que representaba a la Unidad Popular en su seno, en circunstancias que habían barrido totalmente el Gobierno? ¿Qué hubiera ocurrido si los militares sacan a la fuerza a la gente? Mejor que renunciaran o se fueran si comprendían el proceso que se estaba viviendo. Mi propósito era salvar a la corporación de ser intervenida por los militares. Porque todos los que estaban ahí eran representantes de partidos.

\section{VIENTOS DE INTERVENCIÓN}

A fines de septiembre, empezaron a soplar fuerte los vientos de intervención desde la sede Valparaíso de la Universidad de Chile. Según Boeninger, eso no fue provocado originalmente por los militares, sino "por los académicos anti UP de Valparaíso que acordaron pedir a las Fuerzas Armadas que "limpiaran la Universidad de Chile de la influencia marxista'. Fue una petición de los profesores", me dijo enfático el ex rector.

En esa ocasión, Boeninger fue a Valparaíso y tuvo una reunión "muy desagradable, con alrededor de cuarenta profesores, con y sin partido, que estaban contra la Unidad Popular”. Describió así el episodio:

-Ellos habían sentido que los de la UP los habían tratado de sacar a toda costa de la Universidad. En los ghettos controlados por la Unidad Popular, como el Pedagógico de Valparaíso y la Facultad de Ciencias Naturales, había una tensión muy grande. Cuando fui a la reunión, me encontré con que estos académicos estaban en contacto con la Marina y querían que la Marina "entrara a limpiar". Me decían a mí: "No se preocupe rector, alguien tiene que hacer el trabajo sucio".

Boeninger manifestó su total desacuerdo con ese planteamiento:

—Yo no acepto ese criterio — les dije—. Si hay que hacer alguna reestructuración tendrán que hacerla los universitarios, pero con otro criterio. 


\section{CITA EN REÑACA}

La Marina asumió desde el primer instante altas responsabilidades en la Educación. Al ministro de esos primeros días, José Navarro Tobar ${ }^{21}$, un profesor de historia de la Escuela Militar, masón, lo sustituyeron a las pocas semanas por el almirante Hugo Castro Jiménez, hasta ese momento director de Litoral y Marina Mercante. Castro era hombre de confianza del almirante Arturo Troncoso Daroch ${ }^{22}$, uno de los autores del Golpe. Fue ministro hasta 1975, cuando lo sucedió el propio almirante Troncoso, quien antes fue ministro de Vivienda.

El almirante Castro vivía en Reñaca y, a través de un amigo común, Boeninger arregló una entrevista con él.

-Yo no lo conocía, pero partí a verlo con ese amigo, por ahí por el 25 de septiembre, inmediatamente después de la reunión con los académicos. Fue una conversación muy simpática en la casa de Hugo Castro. Le planteé mi punto de vista.

Recuerda Edgardo Boeninger que después de haberle comentado mucho rato sobre la Universidad y las características especiales que tenía, la conversación terminó con estas palabras del almirante Castro:

-Mire, rector, la verdad es que nosotros hemos intervenido la Empresa Portuaria y resulta que en la Universidad hay muchos más marxistas que en la Empresa Portuaria. ¿Cómo quiere usted que no intervengamos la Universidad?

Obviamente, no había más que hablar. Boeninger en ese momento contestó:

- Lo siento mucho, almirante. Yo creo que discrepamos. Voy a pensar qué curso de acción tomar.

\section{LA RENUNCIA DE BOENINGER}

Esa misma tarde Edgardo Boeninger se volvió a Santiago y citó a sus amigos y a la comunidad universitaria al Salón de Honor de la Universidad de Chile.

Habían transcurrido más de quince días desde aquella asamblea en la víspera del Golpe. El Salón de Honor volvía a estar repleto. No eran las mismas personas las que ahí se congregaban ni los mismos motivos de reunión. Esta vez, el protagonista principal fue el rector Edgardo Boeninger, quien tomó el papel en el que traía escrita su decisión y leyó el texto en que explicaba por qué dejaría la rectoría:

Durante cuatro años he desempeñado el cargo de Rector de la Universidad de Chile. Ha sido un período duro, de lucha constante y frontal contra quienes pretendieron someterla a un insensato afán de conquistar el poder total. La Universidad, sin embargo, supo en este tiempo mantener su independencia y preservar sus más auténticos valores gracias a la fe,

21. José Navarro Tobar después fue embajador de Pinochet en El Salvador. Falleció el 4 de enero de 1983.

22. El contraalmirante Arturo Troncoso Daroch fue contralor de la Armada en 1974 y ministro de Vivienda y Urbanismo en 1974 y 1975. 
la solidez y la acción tenaz de la comunidad de académicos, trabajadores y estudiantes que optó mayoritariamente por defender la democracia y el pluralismo.

Producida la inevitable y necesaria caída del gobierno de la UP, estimé que era mi obligación hacer presente mi convicción de que el aporte de las universidades a la tarea de pacificación y reconstrucción nacional debía realizarse en el marco de su propia institucionalidad y que correspondía a los universitarios, gobernándose a sí mismos, asumir la plena responsabilidad de lo que hubiera que hacer. Sentí también que mi permanencia en el cargo quedaba sujeta a la posibilidad de materializar tal solución. La Junta después de un meditado y profundo análisis, estimó necesario tomar una decisión diferente. Mi misión en consecuencia ha terminado.

- Creo que fue un lunes en la tarde y ahí, sin mayores preámbulos, hice una breve síntesis de lo que estaba pasando. Manifesté que en esas condiciones no tenía más que hacer y, por eso, renunciaba a mi cargo ante la comunidad universitaria. Me fui de la asamblea del Salón de Honor a mi casa.

\section{CON LA PISTOLA EN LA MESA}

Hasta el momento de su renuncia a la rectoría de la Universidad de Chile, Edgardo Boeninger no había tenido reunión con la Junta de Gobierno. Estaba, en cambio, en contacto con los rectores de las otras universidades, y como la intervención se empezaba a plantear ya por diferentes lados, los invitó a su casa para conversar sobre el asunto. Faltó Enrique Kirberg, el rector de la Universidad Técnica — actual Universidad de Santiago-, quien era militante comunista y fue detenido y enviado a la isla Dawson. Tampoco pudo estar Fernando Castillo Velasco, de la Universidad Católica, quien estaba enfermo. Asistió en su reemplazo el abogado Alfredo Etcheberry, en ese entonces vicerrector académico de la UC.

Por acuerdo "casi unánime", los rectores decidieron oponerse a cualquier intervención de las universidades y acordaron que el vocero fuera Boeninger. La voz disidente fue la del entonces rector de la Universidad Austral de Valdivia, William Thayer, "el único que manifestó que aceptaría lo que los militares dijeran”, según Boeninger.

La misma tarde de su renuncia Edgardo Boeninger recibió el llamado de un amigo abogado, profesor de la Universidad de Chile, que tenía contacto con los militares.

- Me dijo que la Junta de Gobierno estaba consternada con mi renuncia y me planteó si estaba dispuesto a conversar con sus integrantes. Respondí positivamente y se organizó una reunión con los cuatro uniformados en el Ministerio de Defensa. Ellos me pidieron que me acompañara el doctor René Orozco, vicerrector de la sede Norte y hermano del general Héctor Orozco ${ }^{23}$. A mi vez, dije que quería ir con Enrique D’Etigny.

23. Héctor Orozco Sepúlveda, coronel de Ejército al momento del Golpe militar, estaba al mando del Regimiento Yungay en la ciudad de San Felipe, lo que le ha significado afrontar un proceso por la desaparición de seis personas en esa ciudad. En 1977, ya ascendido a general, fue designado por Augusto 
Este es el relato de Boeninger sobre ese encuentro:

-Estaban Pinochet, Merino, Leigh y Mendoza. Yo lo hablé todo y les dije que iba como presidente del Consejo de Rectores y que opinaría en nombre de todos. Estaba también el general Rolando González, que era el secretario de la Junta, pero no invitaron al ministro de Educación. Nos sentamos. Pinochet se ubicó a la cabecera. Merino sacó una pistola y la puso arriba de la mesa.

-Bueno -dijo Pinochet-, quisiéramos escuchar las palabras del señor rector.

-Me largué un discurso muy diplomático — recordaba Boeninger-. Hablé de la autonomía académica, dije que consideraba un profundo error que se pensara intervenir la Universidad. No hicieron ningún comentario, salvo Leigh, que fue el más cordial.

- Hemos escuchado una exposición muy seria del señor rector —indicó el general Leigh-. Creo que tenemos que meditar lo que usted nos ha planteado. Yo le quisiera preguntar si usted está dispuesto a entregar un memorando.

-No tengo ningún inconveniente — respondió Boeninger.

—Después de esta reunión, usted no insistirá en su renuncia, rector —intervino el almirante Merino.

—Eso dependerá del curso de acción que decidan ustedes en definitiva; no depende de mí - respondió el rector.

Después de la reunión, Edgardo Boeninger mandó un memorando a la Junta. El escrito partía señalando "objetivos comunes".

-Puse algunos conceptos como "reconciliación”, "paz" y otras palabras de ese tipo. Pasaron como cuatro días en que parece que la Junta meditó qué hacía con este lío. Yo recibía informaciones a través de personas que me llamaban por teléfono a mi casa, pero lo más interesante fue la intervención de René Silva Espejo, el director del diario El Mercurio que era muy amigo mío. Él se jugó porque se aceptara el planteamiento en el sentido de que los militares dejaran la Universidad tranquila y que nosotros podríamos hacer procesos de verificación de la calidad académica de los profesores, pero que esto era asunto de los universitarios. Silva Espejo me llamaba y me decía: "Las cosas van bien".

Unos días después, el viernes 28 de septiembre se produjo la segunda invitación. "A esa reunión fueron todos menos William Thayer, y asistieron, además, el secretario ejecutivo del Consejo de Rectores Iván Lavados y el asesor jurídico, Máximo Pacheco Gómez. Había mucha expectación, prensa, fotógrafos. Era el primer incidente que tenía la Junta Militar con gente que no era del gobierno depuesto", en palabras de Boeninger.

- Nos hicieron entrar. Estaban los cuatro integrantes de la Junta más el comandante Hugo Castro, que ya había jurado como ministro de Educación. A un lado Pinochet, Merino y yo. Al frente Leigh y Mendoza. Todos los demás rectores, más acá. Después de los saludos, nos sentamos.

Pinochet en un cargo clave: director de la Dirección de Inteligencia del Ejército, DINE. Posteriormente, apareció involucrado en procesos vinculados al asesinato del ex canciller Orlando Letelier en Washington —en el denominado "caso pasaportes" y en las declaraciones de Pedro Espinoza Bravo, quien lo acusó de inducirlo a mentir para resguardar a Pinochet- Entre los cargos que tuvo bajo la dictadura figura el de director ejecutivo del Canal Nacional de Televisión. 
Merino volvió a sacar la pistola y la colocó de nuevo sobre la mesa. En eso se abrió la puerta y entraron en tropel los camarógrafos de televisión. Merino pescó la pistola y la escondió. Sonrisas. Fotos. Se fueron los gallos y ipaf! La pistola arriba de nuevo. Nunca entendí esta obsesión por ponerla sobre la mesa. Deduzco que debe ser un problema de reglamento, de seguridad - me comentaba Boeninger.

Augusto Pinochet, presidente de la Junta de Gobierno de Chile, abrió la sesión:

-Aquí están los señores rectores. Ya hemos escuchado al rector Boeninger. ¿Quiere agregar algo?

—No, no tengo nada que agregar — respondió el aludido.

— ¿Los demás señores rectores? —inquirió Pinochet, dirigiendo su mirada hacia ellos.

Los rectores se quedaron callados, como lo tenían previsto. Boeninger era el vocero y ya había manifestado su punto de vista por escrito.

— ¿Esto significa que los rectores están de acuerdo con los planteamientos del rector Boeninger? — preguntó Pinochet.

Silencio.

-Pues bien, el gobierno actual, la Junta de Gobierno está en total desacuerdo. El almirante Castro dará las razones.

Sentado a la izquierda de Boeninger, el almirante Castro tenía en sus manos el memo del rector de la Universidad de Chile. Tomó la palabra:

- Tengo el memorando del rector Boeninger. Y por ejemplo, aquí, al comienzo, dice "Objetivos comunes". No hay objetivos comunes. Los únicos objetivos son los de la honorable Junta de Gobierno y todos los demás ciudadanos tienen la obligación de obedecer de manera incondicional.

Estaba todo dicho.

Después de ese comentario, Boeninger se echó para atrás, "miré a los demás rectores y me sonreí. Concluí que eso era un show. ¡Qué voy a escuchar a ese tipo! A partir de ese momento me desconecté y no podría recordar qué cosas más dijo. A esa altura me daba lo mismo. Me imagino que habló unos quince minutos, parece que de los marxistas, la subversión y no sé cuántas cosas más".

Solo al final el ex rector recordaba que el almirante Castro terminó diciendo: "Hemos decidido nombrar rectores delegados".

Después del anuncio, tomó la palabra Pinochet y mirando a Boeninger volvió a ofrecer la palabra.

— No tengo nada que comentar — sentenció Boeninger.

— ¿Algún otro de los señores rectores? —insistió Pinochet.

Dos personas pidieron la palabra. Uno fue Alfredo Etcheverry, vicerrector de la Universidad Católica, el famoso abogado penalista, quien preguntó:

-Mire, general, ¿por qué en lugar de denominarlos "rectores-delegados" no los llama simplemente "delegados"?

Según Boeninger, parece que los uniformados no entendieron la broma. Los rectores apenas podían reprimir la risa.

Entonces, Pinochet volvió a ofrecer la palabra. 
Después, continúa el relato de Boeninger, "vino la parte más absurda de la reunión, cuando intervino el rector Campos de la Universidad del Norte, a quien le decíamos Campitos. Era un ex cura que había sido bastante partidario de la UP, quien después de identificarse y de meter dos frases de su currículo agregó: 'Yo quiero decirle, general, que tengo mucha experiencia en los asuntos universitarios y quiero ponerme a disposición de ustedes para poderlos asesorar en lo que fuere necesario"'.

Silencio del resto. Miradas torvas hacia Campitos de los demás rectores, y se levantó la sesión.

La autonomía de las universidades terminaba. El Golpe en la cátedra cambiaría el destino de las universidades chilenas. Había llegado la hora de la mano militar.

Después todo sería muy distinto para la Universidad de Chile. A la represión de los primeros meses, donde hubo todo tipo de atropellos "en nombre de la Seguridad Nacional" contra académicos, trabajadores y estudiantes, se sumó muy luego otra acción implacable: la de los economistas de Chicago provenientes de la Universidad Católica que en extraña simbiosis con el gremialismo de Jaime Guzmán Errázuriz impondrían sus ideas y su modelo de educación. 